\title{
COMÉRCIO E SERVIÇOS EM ÁREAS URBANAS DE GÉNESE ILEGAL. \\ O CASO DA QUINTA DO CONDE (SESIMBRA - PORTUGAL)
}

RICARDO TOMÉ ${ }^{1}$

\begin{abstract}
Resumo - A construção feita sem autorização das Câmaras Municipais, a quem compete licenciar e controlar as obras realizadas por particulares, ocorreu em massa nas Áreas Metropolitanas de Lisboa e do Porto, na segunda metade do século XX. A sua natureza ilegal fez com que as boas práticas urbanísticas não fossem levadas em conta, originando problemas no espaço urbano e condicionando a sua organização e evolução. A Quinta do Conde (Sesimbra) foi uma Área Urbana de Génese Ilegal (AUGI), cujos primeiros loteamentos surgiram na década de 1960; entretanto, vários factores contribuíram para reforçar a sua atractividade, gerando intensas dinâmicas populacionais, construtivas e funcionais. Desde a sua génese, a oferta de comércio e de serviços registou profundas mutações, passando de um comércio predominantemente associado ao alimentar e à construção civil, com uma estruturação incipiente e de carácter familiar, para uma oferta mais diversificada de produtos, alguns deles com especialização, num ambiente urbano mais estruturado.
\end{abstract}

Palavras-chave: Áreas Urbanas de Génese Ilegal, suburbanização, comércio, serviços, Quinta do Conde (Sesimbra), Portugal.

\begin{abstract}
TRAde AND SERVICES IN URban AREAS DEVEloped ILlegally: THE Case of Quinta do Conde (Sesimbra, Portugal). During the second half of the $20^{\text {th }}$ century there was a massive surge of illegal building in the metropolitan areas of Lisbon and Oporto. Houses were built without the proper licenses issued by the Municipalities that are also responsible for the supervision of constructions by private individuals. As a result of the building illegal nature, good urban planning practices were not taken into account; this led to problems in urban space and compromised its organization and evolution. Quinta do Conde (Sesimbra) was an Urban Area developped illegaly (AUGI, the Portuguese acronym), whose first allotments were made in the 1960s. However, several factors have contributed to enhance its appeal, generating intense, constructive and functional population dynamics. The offer of trade and services exhibited deep changes since its inception,
\end{abstract}

Recebido: Abril 2012. Aceite: Novembro 2013.

1 Colaborador do e-GEO, Centro de Estudos de Geografia e Planeamento Regional (FCSH/ UNL) e Bolseiro de Investigação no Núcleo de Urbanismo e Ambiente do CESUR, Instituto Superior Técnico. E-mail: rjatome@gmail.com 
shifting from a business predominantly associated with food trade and construction, which had an incipient structure and familial organisation, to a more diversified product range, some of which quite specialised, in a more structured urban environment.

Keywords: Urban Areas develloped illegallly, suburbanisation, trade, services, Quinta do Conde (Sesimbra), Portugal.

Résumé - ÉVOLUTION DU COMMERCE ET DES SERVICES DANS LES AIRES URBAINES Dites «CLANDestines». Le CAS DE La Quinta do Conde (Sesimbra, Portugal). Pendant la seconde moitié du XX $X^{\text {ème }}$ siècle, beaucoup de constructions furent faites sans autorisation (acronyme en Portugais : AUGI) dans les Aires métropolitaines de Lisbonne et de Porto. Il en résulta de mauvaises pratiques urbanistiques, qui ont conditionné leur organisation et leur évolution. La Quinta do Conde (Sesimbra), située $30 \mathrm{~km}$ au sud de Lisbonne, en est un exemple. Les premiers lotissements y apparurent pendant les années $60 \mathrm{du}$ siècle passé, mais son développement principal est beaucoup plus récent. On y observe de profondes modifications des types de commerce et de services, à l'origine peu structurés, de type familial et concernant surtout les produits alimentaires et la construction civile, aujourd'hui ils sont bien plus diversifiés et même spécialisés, et mieux structurés.

Mot-clés: Aires urbaines de genèse illégale (AUGI), suburbanisation, commerce, services, Quinta do Conde (Sesimbra), Portugal.

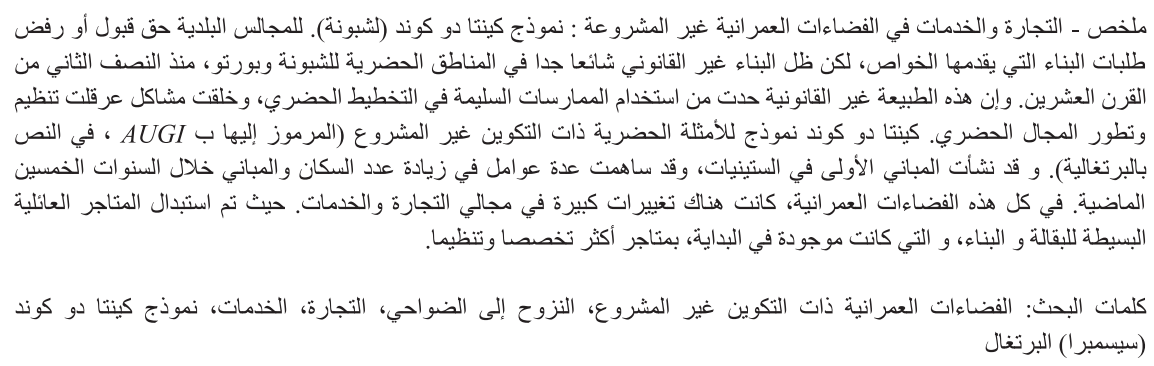

\section{INTRODUÇÃO}

Os loteamentos clandestinos ${ }^{\mathrm{i}}$ marcaram o crescimento das Áreas Metropolitanas de Lisboa e do Porto desde a década de 50, contribuindo para a expansão da habitação nas suas periferias, num contexto social e económico complexo, no qual se podem diferenciar, pelo menos, duas fases - antes e depois de 1974. A carência de habitação que está na origem deste fenómeno, nessa primeira fase, é uma consequência da industrialização que despoletou o êxodo rural em direcção às principais cidades industriais do litoral; na segunda fase, estes fluxos abrandaram mas actuaram outros factores de natureza política decorrentes da mudança de regime, como o retorno dos portugueses residentes nas ex-colónias africanas (1975-76) e o aumento da população imigrante oriunda dos países africanos de língua oficial portuguesa (PALOP). O crescimento destes novos aglomerados populacionais levou à implantação dos primeiros estabelecimentos de comércio e de serviços, por iniciativa de alguns 
residentes, quase sempre mulheres, na busca de um complemento ao rendimento familiar. Não raro reproduziam modelos tradicionais das suas áreas de origem, que estavam longe de cumprir os requisitos legais exigidos.

Os estudos sobre loteamentos clandestinos e AUGI têm abordado preferencialmente questões relacionadas com a habitação (Barata Salgueiro, 1977 e 1983; Bruno Soares, 1982; Matos, 1990) e a reconversão urbanística (Barata Salgueiro, 1972; Nunes da Silva e Pereira, 1986; Bruno Soares, 1984, 1987 e 1989; Guerra e Fonseca Ferreira, 1990; Arrabaça, 2002; Costa, 2008). Na década de 80, esta questão estava na ordem no dia, o que pode ser atestado pelos seguintes eventos: a organização das Jornadas Nacionais sobre Loteamentos Clandestinos, em 1981, e das Novas Jornadas Nacionais sobre Loteamentos Ilegais, em 1983; e a selecção desta temática para o primeiro número da revista Sociedade e Território, em 1984.

Este artigo, elaborado a partir da dissertação de mestrado em Gestão do Território apresentada na FCSH/UNL (Tomé, 2011), visa: relacionar a evolução geográfica e funcional do comércio e serviços em espaços urbanos de génese ilegal com as transformações ocorridas no território nos últimos trinta anos, tendo por base o exemplo da Quinta do Conde (Sesimbra); caracterizar e perspectivar a evolução do comércio e dos serviços na área de estudo; e compreender o papel dos diversos agentes na evolução temporal e espacial das actividades económicas. A metodologia para a sua realização privilegiou, numa primeira fase, a análise de bibliografia e legislação sobre loteamentos clandestinos e AUGI e a "reconstituição", através de fontes documentais e directas, da evolução da Quinta do Conde; numa segunda fase, fez-se um levantamento funcional de todos os estabelecimentos de comércio e de serviços da Quinta do Conde ${ }^{\mathrm{ii}}$, que permitiu conhecer em pormenor a sua estrutura (uma vez que nenhuma entidade tinha esta informação recolhida) e articular algumas características com a origem, natureza e evolução urbanística do aglomerado.

\section{DOS LOTEAMENTOS CLANDESTINOS ÀS ÁREAS URBANAS DE GÉNESE ILEGAL (AUGI)}

Em meados da década de 40 do século XX, a competência para urbanizar e parcelar terrenos era exclusiva da administração pública, mas esta não tinha nem capacidade nem meios para a realizar (Matos, 1990). O direito de loteamento dos privados só foi contemplado pelo DL 46647, de 29 de Novembro de 1965, mediante uma licença requerida à Câmara Municipal; caso contrário, o loteamento seria considerado ilegal, ficando os seus proprietários sujeitos ao pagamento de uma coima. Ainda que os primeiros bairros clandestinos surgissem na década de 30, foi entre as décadas de 60 e 80 que tiveram maior repercussão, não tendo o DL 46647 impedido ou mitigado o fenómeno. De acordo com Arrabaça (2002), estima-se que $42 \%$ dos fogos construídos em Portugal nesse período tiveram génese ilegal.

Barata Salgueiro (2005: 325) define estes bairros como "construções de alvenaria de tipo e de qualidade muitas vezes semelhante às da construção legal, sobre solos pertencentes aos ocupantes, adquiridos por estes com o propósito de construção, 
através de um processo de loteamento ilegal, constituindo conjuntos perfeitamente individualizados de construção." Costa (2008:3) adverte que "um bairro clandestino não é necessariamente um bairro degradado ou bairro de lata, constituído maioritariamente por barracas de madeira ou chapa metálica em risco de ruína, com poucas ou nenhumas condições de higiene e salubridade e sem acesso a água potável ou electricidade. Também não é necessariamente uma zona de isolamento por diferenciação e/ou discriminação económica, social, étnica, cultural ou religiosa, vulgo ghetto. Um bairro clandestino, nomeadamente em Portugal pode, de facto, apresentar pontualmente algumas características isoladas, encobertas ou diluídas destas duas últimas definições, mas no caso geral, a realidade no terreno mostra-nos um cenário bem diferente." Acrescenta o mesmo autor (2008: 80) que "as AUGI não são todas iguais e um número substancial passará inclusive bastante despercebido ao público em geral, dadas as suas semelhanças com outras zonas legais."

Os loteamentos clandestinos expandem-se em contextos políticos, sociais e económicos específicos. Numa primeira fase (até 1974) justificam-se: pelas limitações das políticas urbanísticas e habitacionais do Estado Novo que, devido ao desemprego e inflação, geraram especulação fundiária, contribuíram para o rápido aumento dos preços das casas, o aparecimento de formas precárias de habitação (por exemplo bairros de lata) e a sublocação e superlotação de fogos; pelo acelerado crescimento das áreas metropolitanas e litorais do país, resultante da concentração de investimentos económicos e processos de industrialização em áreas urbanas e do êxodo rural que desencadeou; pelo elevado crescimento natural da população; e pelos baixos salários praticados, o principal vector do crescimento económico. Após 1974 assistiu-se: ao regresso de 150000 famílias das antigas colónias portuguesas; à entrada de população imigrante oriunda dos PALOP; ao congelamento das rendas em Lisboa e Porto; e à política de concessão de crédito habitação facilitada, que permitiu a aquisição de primeira ou segunda residência e, noutros casos, a sua autoconstrução (Matos, 1990; Arrabaça, 2002; Costa, 2008).

Para a proliferação de bairros clandestinos contribuíram ainda um conjunto de aspectos culturais, como a importância de possuir solo, para deixar aos herdeiros (em geral os filhos); a ideia de que o regime político e a economia eram instáveis, pelo que a aquisição da habitação era uma salvaguarda das poupanças individuais e que nalguns casos podia ser potenciada para o desenvolvimento de actividades económicas (por vezes, a tempo parcial, para complemento do rendimento); o formato da habitação típica do clandestino (moradia, em áreas de baixa densidade, com quintal e garagem); e o desejo dos estratos sociais mais elevados adquirirem segunda habitação, para fins-de-semana ou férias. Há, neste contexto, uma combinação entre aspirações de mais bem-estar no presente e uma ideia de melhor futuro para si e para os filhos (Matos, 1990; Santos, 2008).

Para tentar pôr fim aos loteamentos ilegais e reconverter as áreas já existentes foram publicados vários diplomas. O primeiro foi o 275/76, de 13 de Abril, que representa uma evolução do DL 289/73 (loteamentos urbanos), de 6 de Junho, que já previa sanções severas, como a posse administrativa e a demolição do edificado. 
Todavia, estas medidas revelaram-se ineficazes, devido à morosidade da execução judicial e à célere dinâmica do fenómeno. Posteriormente, destacam-se o DL 804/76, de 6 de Novembro, relativo à recuperação de áreas clandestinas, exigindo às câmaras municipais a apresentação de todas as Áreas Críticas de Recuperação e Reconversão Urbanística ao ministério que tutelava o urbanismo, com o objectivo de definir áreas para a implantação de equipamentos e infra-estruturas, eventuais correcções do desenho urbano e a repartição das despesas entre os proprietários e a administração pública); o DL 152/82, de 3 de Maio (alterado pelo DL 210/83, de 23 de Maio) sobre a criação de Áreas de Desenvolvimento Urbano Prioritário, as quais deveriam suportar o desenvolvimento urbano por um período máximo de 5 anos (incluindo todas as componentes urbanísticas indispensáveis para a sua qualidade) e colocar no mercado, a preço justo, os terrenos que os proprietários não pretendiam urbanizar; o DL 400/84, de 31 de Dezembro que estabelece o Novo Regime de Loteamentos, tentando controlar os loteamentos ilegais, através de medidas como a criação de obstáculos à venda de propriedades em avos, sanções pecuniárias e prisionais mais severas para novos loteamentos ilegais e a possibilidade de qualquer interessado obter previamente informações sobre a legalidade de eventuais construções; e, finalmente, a Lei 91/95, de 2 de Setembro, relativa à reconversão das AUGI, definindo os trâmites processuais e exigindo aos proprietários ou comproprietários dos lotes clandestinos que suportassem os encargos com a infra-estruturação. Este foi o diploma legal que se revelou mais eficaz na mitigação do fenómeno e na consciencialização dos proprietários quanto às suas obrigações no processo de legalização e reconversão das AUGI (quadro I).

Quadro I - Objectivos e resultados obtidos com a Lei 91/95, de 2 de Setembro.

Table I-Objectives and results obtained with the Law 91/95 of 2 september.

\begin{tabular}{|c|c|c|}
\hline Objectivos iniciais & Situação existente & Objectivos alcançados \\
\hline $\begin{array}{l}\text { - Desincentivar o surgimento de } \\
\text { loteamentos ilegais; } \\
\text { - Integrar e reconverter as AUGI } \\
\text { existentes; } \\
\text { - Estimular a iniciativa privada } \\
\text { para a reconversão urbanís- } \\
\text { tica; } \\
\text { - Definir competências, deve- } \\
\text { res e âmbito dos órgãos da } \\
\text { administração; } \\
\text { - Envolver todos os proprietá- } \\
\text { rios na reconversão, evitando } \\
\text { bloqueios de minorias; } \\
\text { - Estipular um limite temporal } \\
\text { para a resolução do problema. }\end{array}$ & $\begin{array}{l}\text { - Processo de reconversão das } \\
\text { AUGI moroso ou parado; } \\
\text { - Forte correlação entre a } \\
\text { lentidão do processo e a } \\
\text { morosidade na apreciação } \\
\text { dos planos na administração } \\
\text { central; } \\
\text { - Prazos definidos para as } \\
\text { administrações das AUGI } \\
\text { participarem no processo } \\
\text { de reconversão ultrapassa- } \\
\text { dos sistematicamente; } \\
\text { - Omissões da regulamenta- } \\
\text { ção de loteamentos ilegais } \\
\text { destinados ao comércio e à } \\
\text { indústria. }\end{array}$ & $\begin{array}{l}\text { - Não houve um aumento } \\
\text { expressivo de loteamentos } \\
\text { ilegais; } \\
\text { - A maioria dos processos de } \\
\text { reconversão foi de iniciativa } \\
\text { privada; } \\
\text { - Maior consciencialização e } \\
\text { envolvimento de todos os } \\
\text { agentes. Alguns municípios } \\
\text { desenvolveram conhecimento } \\
\text { específico consubstanciado em } \\
\text { boas práticas; } \\
\text { - As minorias, desinteressadas } \\
\text { na reconversão, não tiveram } \\
\text { capacidade para se afirmar } \\
\text { como força de bloqueio. }\end{array}$ \\
\hline
\end{tabular}

Fonte: Adaptado de Costa (2008) 
Estes bairros, ao surgirem sem intervenção do Estado, apresentavam graves problemas urbanos, como a falta ou insuficiência de infra-estruturas, de espaços públicos, de áreas para equipamentos, de transportes públicos, assim como arruamentos precários desorganizados e deficiências nos sistemas de recolha do lixo, saneamento e fornecimento de água e energia. Existiam aglomerados que se localizavam junto de postes de alta tensão, em áreas muito declivosas ou inundáveis ou, ainda, em zonas non ædificandis, como aconteceu nos concelhos de Loures e Odivelas (Barata Salgueiro, 1977; Arrabaça, 2002; Costa, 2008).

A expansão destes aglomerados populacionais favoreceu o aparecimento de actividades económicas locais, com destaque para o comércio e os serviços de proximidade. Como refere Cachinho (2002: 108), "o comércio faz parte da razão de ser dos aglomerados urbanos; viabiliza a sua existência, explica a sua organização interna e justifica muito do movimento e animação que nestes acontece." Barata Salgueiro (1989: 153) já defendia esta ideia e salientava que o comércio promove "o convívio entre as pessoas e a animação dos lugares, para além de ser um elemento decisivo na estruturação do espaço. (...) [A] função permanece mesmo quando mudam as formas ou as características dos estabelecimentos." Assim, importa analisar como a génese ilegal de um aglomerado populacional influenciou a estruturação e organização da oferta de comércio e serviços.

\section{COMÉRCIO E SERVIÇOS EM ESPAÇOS SUBURBANOS}

Nas últimas décadas, o comércio e os serviços sofreram profundas mutações, a um ritmo cada vez mais célere e com uma crescente complexidade. Estas mudanças, fortemente impulsionadas pela integração na $\mathrm{CEE} / \mathrm{UE}$, ocorreram a vários níveis: organização da distribuição (maior concentração de insígnias por grupos económicos, adopção de novas técnicas de logística e distribuição e novos padrões geográficos dos estabelecimentos comerciais em função da sua dimensão e graus de especialização) e perfis dos consumidores (variações do poder de compra, novas formas de família, aumento do grau de escolarização, feminização do mercado de trabalho, envelhecimento da população, imigração, redução e diversificação dos horários de trabalho, revolução do frio doméstico, atitudes consumistas versus consumeristas $^{\text {iii }}$, o que origina novos e diversificados perfis de consumidor). Em paralelo, as cidades organizam-se segundo um modelo centrífugo e multipolar, modificando as suas relações no sistema urbano, em reflexo dos investimentos em infra-estruturas de transporte e do concomitante aumento do uso do transporte individual motorizado. Nas áreas metropolitanas as dinâmicas territoriais têm favorecido a expansão das periferias e das actividades de comércio e serviços que nelas se desenvolvem, pelos motivos sintetizados no quadro II. 
Quadro II - Factores explicativos do declínio dos centros urbanos consolidados e da maior atractividade das periferias urbanas. Table II - Factors that explain the decline in consolidated urban centres and the appeal of urban peripheries.

\begin{tabular}{|c|c|c|}
\hline & $\begin{array}{l}\text { Factores de rejeição } \\
\text { do meio urbano denso }\end{array}$ & $\begin{array}{l}\text { Factores de atracção } \\
\text { da periferia }\end{array}$ \\
\hline $\begin{array}{l}\text { Oferta } \\
\text { fundiária e } \\
\text { imobiliária }\end{array}$ & $\begin{array}{l}\text { Preços elevados; pouca oferta de novos es- } \\
\text { paços; inadequação dos espaços às funções. }\end{array}$ & $\begin{array}{l}\text { Maior disponibilidade de solo e preços } \\
\text { mais acessíveis; diversificação de produtos } \\
\text { imobiliários. }\end{array}$ \\
\hline $\begin{array}{l}\text { Transportes e } \\
\text { acessibilidade }\end{array}$ & $\begin{array}{l}\text { Problemas de acessibilidade; problemas de } \\
\text { estacionamento. }\end{array}$ & $\begin{array}{l}\text { Existência de parqueamento; oportunida- } \\
\text { des ligadas a novas redes e nós (intersec- } \\
\text { ção das radiais com as novas circulares). }\end{array}$ \\
\hline $\begin{array}{l}\text { População e } \\
\text { valores }\end{array}$ & $\begin{array}{l}\text { Envelhecimento e empobrecimento da po- } \\
\text { pulação; insegurança; ruído e poluição. }\end{array}$ & $\begin{array}{l}\text { Periurbanização do emprego e da habita- } \\
\text { ção; modernidade associada aos novos es- } \\
\text { paços urbanos em desenvolvimento. }\end{array}$ \\
\hline Empresas & $\begin{array}{l}\text { Emergência de grandes grupos com fórmu- } \\
\text { las estandardizadas; reagrupamento das ac- } \\
\text { tividades na sequência de fusões. }\end{array}$ & $\begin{array}{l}\text { Sítios sem passado e com possibilidades } \\
\text { múltiplas; custo de implantação em geral } \\
\text { reduzido; proximidade a outras empresas. }\end{array}$ \\
\hline Atividades & $\begin{array}{l}\text { Crescimento das necessidades em termos } \\
\text { de superfícies; reduzida flexibilidade dos } \\
\text { espaços. }\end{array}$ & $\begin{array}{l}\text { Melhor organização da gestão, da logística } \\
\text { e do trabalho. }\end{array}$ \\
\hline $\begin{array}{l}\text { Políticas } \\
\text { dos poderes } \\
\text { públicos }\end{array}$ & $\begin{array}{l}\text { Restrições do uso do solo; congestionamen- } \\
\text { to urbano; planos de circulação e de esta- } \\
\text { cionamento; custo do estacionamento; fis- } \\
\text { calidade. }\end{array}$ & $\begin{array}{l}\text { Política de zonamento; ordenamento das } \\
\text { grandes infra-estruturas e dos parques de } \\
\text { actividades; vantagens concedidas pelas } \\
\text { autarquias. }\end{array}$ \\
\hline
\end{tabular}

Fonte: Adaptado de Alves (2005)

A evolução da mancha urbana e dos espaços de comércio e serviços passou por diversas fases, que vão desde a hegemonia do centro de cidade ${ }^{\text {iv }}$ tradicional até aos modelos multipolares complexos (fig. 1).

Se aplicarmos este modelo à área metropolitana de Lisboa, na fase 1 (até 1980), o comércio e os serviços localizavam-se no centro da cidade, exercendo um forte poder de atracção sobre os consumidores. Com a expansão da residência e do comércio na periferia, vão surgindo novos territórios, que lhe retiram a hegemonia. Na fase 2 (1980-1995) há uma relação de complementaridade entre o centro e a periferia, para a qual contribuiu a abertura de hipermercados (isolados ou com pequenas galerias comerciais), em locais periféricos, com elevada acessibilidade e amplas áreas de influência. Note-se que muitas áreas urbanas periféricas nesta época não tinham organização interna suportada num centro de comércio e serviços. A fase 3 (desde meados dos anos 90) caracteriza-se pela perda de importância relativa do centro da cidade, que experimenta a competição directa da oferta, ancorada em grandes centros comerciais localizados nas áreas suburbanas e que contribuíram para a emergência de um modelo urbano multipolar. Nos últimos anos, reflexo da crise económica, da saturação do modelo consumista ancorado em centros comerciais e em grandes superfícies e da afirmação de novos valores (consumo consciente, sustentabilidade, etc.), o retorno ao centro, a cidade compacta e a compra de proximidade parecem estar a ganhar peso. 


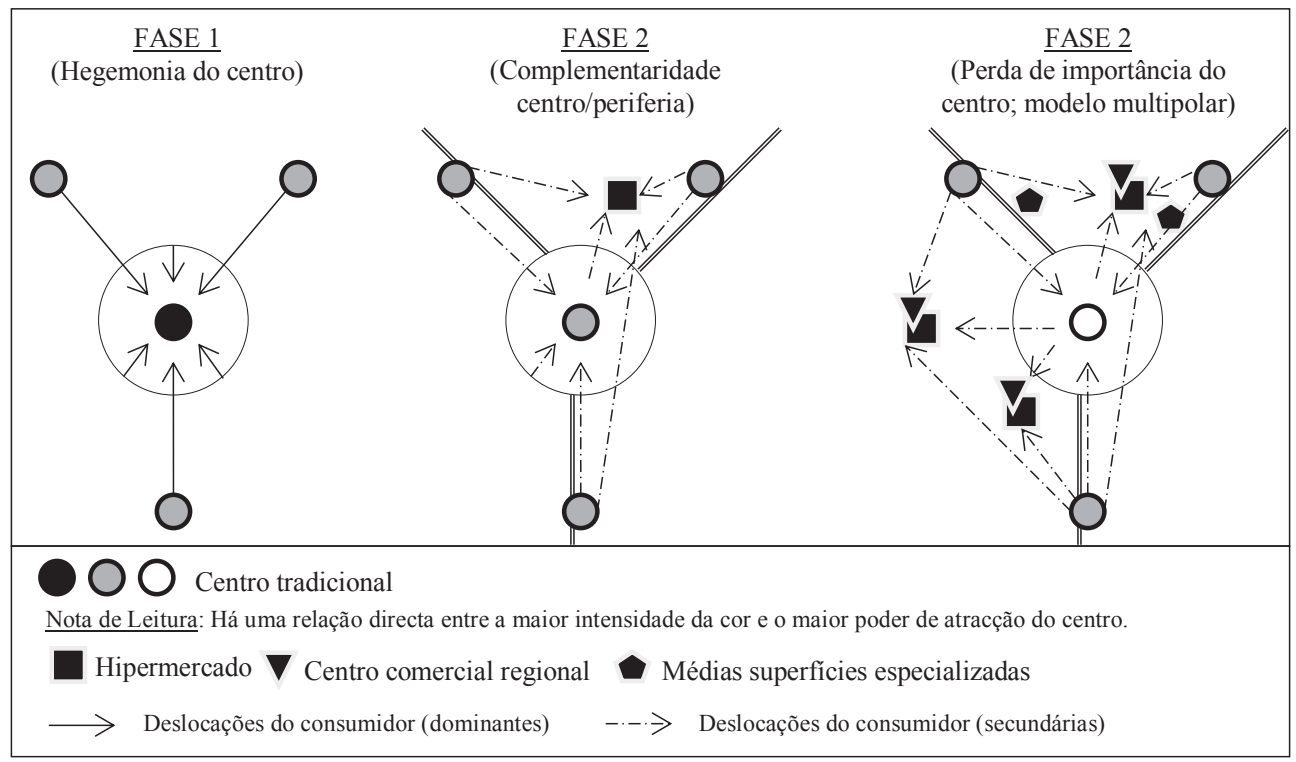

Fig. 1 - Esquema de evolução do comércio e serviços em áreas metropolitanas.

Fig. 1 -Schematic evolution of trade and services in metropolitan areas.

Adaptado de Teixeira (2002), citado em Cachinho (2006).

Merenne-Schoumaker (2003) sintetiza a evolução do comércio em contexto metropolitano (quadro III). É ao nível suburbano que as características referidas para a segunda coroa melhor se adequam à área em estudo (Quinta do Conde).

Quadro III - Dinâmicas de localização comercial em contexto metropolitano.

Table III - Dynamics of commercial location in a metropolitan context.

\begin{tabular}{|c|c|c|c|}
\hline Evolução & Centro da cidade & Primeira coroa & Segunda coroa \\
\hline Estrutural & $\begin{array}{l}\text { Especialização no equipa- } \\
\text { mento pessoal e na cultura- } \\
\text {-lazer; desenvolvimento do } \\
\text { sucursalismo e da franchise. }\end{array}$ & $\begin{array}{l}\text { Desmantelamento dos teci- } \\
\text { dos de comércio banal; de- } \\
\text { saparecimento do comércio } \\
\text { isolado. }\end{array}$ & $\begin{array}{l}\text { Especialização primeiro no } \\
\text { alimentar, depois no equipa- } \\
\text { mento da casa e nos transpor- } \\
\text { tes; diversificação recente para } \\
\text { os sectores mais ligeiros. }\end{array}$ \\
\hline Espacial & $\begin{array}{l}\text { Retracção do hipercentro; } \\
\text { multiplicação dos espaços } \\
\text { pedonais, galerias e centros } \\
\text { associados a operações de } \\
\text { renovação urbana. }\end{array}$ & $\begin{array}{l}\text { Retracção ao nível de cen- } \\
\text { tros secundários ou pólos } \\
\text { de proximidade, baseados } \\
\text { em supermercados ou dis- } \\
\text { counts. }\end{array}$ & $\begin{array}{l}\text { Três fórmulas principais: (i) } \\
\text { polos em torno de hipermer- } \\
\text { cados e de grandes superfí- } \\
\text { cies; (ii) centros comerciais } \\
\text { planeados; (iii) eixos especia- } \\
\text { lizados. }\end{array}$ \\
\hline Qualitativa & $\begin{array}{l}\text { No início, aumento cons- } \\
\text { tante; depois, estagnação ou } \\
\text { diminuição, devido à saída } \\
\text { das insígnias. }\end{array}$ & $\begin{array}{l}\text { Perda de qualidade, excepto } \\
\text { em pontos privilegiados }\end{array}$ & $\begin{array}{l}\text { Aumento recente e sensível } \\
\text { do nível qualitativo, excepto } \\
\text { nos eixos. }\end{array}$ \\
\hline Temporal & \multicolumn{3}{|c|}{ Movimento lento, mas que se acentuou recentemente. } \\
\hline
\end{tabular}

Adaptado de Merenne-Schoumaker (2003) 
Nas periferias urbanas estamos perante um sistema de comércio e serviços complexo, em que coexistem diversos formatos (pequenos estabelecimentos de comércio e serviços, feiras, supermercados, hipermercados, discount, galerias comerciais, centros comerciais, retail parks, outlet factories e franchising, entre outros; dentro destes formatos podemos ainda considerar um vasto leque de subformatos), todos eles com a sua segmentação e posicionamento no mercado, respectiva política de preços, localização e modus operandis bem definidos (quadro IV). No caso português, a complexidade do sistema resultou também do início mais tardio das mudanças no comércio e distribuição e da consequente emergência simultânea de formatos que noutros países europeus ocorreu de forma mais diferida no tempo.

Quadro IV - Principais formas de comércio e serviços em espaço suburbano.

Table IV-Main forms of trade and services in suburban areas.

\begin{tabular}{|c|c|c|c|}
\hline Tipos & Localização & Produto imobiliário & Principais características \\
\hline $\begin{array}{l}\text { Feiras e mercados de le- } \\
\text { vante }\end{array}$ & $\begin{array}{l}\text { Áreas periféricas do aglo- } \\
\text { merado. }\end{array}$ & - & $\begin{array}{l}\text { Asseguram o abastecimento da popula- } \\
\text { ção; privilegiam a satisfação de necessi- } \\
\text { dades básicas não alimentares (vestuário, } \\
\text { calçado, acessórios); tendência para a es- } \\
\text { pecialização quando inseridas em meio } \\
\text { urbano. }\end{array}$ \\
\hline
\end{tabular}

Privilegiam inserção no te- Piso térreo de edifícios cido urbano (lógica de pro-

Supermercados e

Discount ximidade). As unidades de maior dimensão localizam-se em função dos eixos viários periféricos

Bairros residenciais; Prin- Lojas no rés-do-chão. cipais eixos viários.

Mercearias habitacionais.

Edifícios térreos e construídos para o efeito.

Têm dimensão entre 400 e $2500 \mathrm{~m}^{2}$; sortido alimentar e misto com grande peso das marcas próprias. Com ou sem estacionamento próprio.

Satisfazem as necessidades básicas da população, próximo da habitação; devido à concorrência de supermercados, dis-

\begin{tabular}{lll} 
& & \\
Hipermercados & $\begin{array}{l}\text { Eixos viários periféricos, } \\
\text { de grande afluência; piso } \\
\text { térreo de centros comer- } \\
\text { ciais. }\end{array}$ & $\begin{array}{l}\text { Edifícios térreos e am- } \\
\text { plos construídos para o } \\
\text { efeito (podem ter uma } \\
\text { galeria comercial). }\end{array}$ \\
\hline $\begin{array}{l}\text { Outros estabelecimentos } \\
\text { comerciais (alimentares } \\
\text { especializados e não ali- } \\
\text { mentares) e de serviços }\end{array}$ & Ruas mais movimentadas. & $\begin{array}{l}\text { Lojas no rés-do-chão. } \\
\text { Serviços podem surgir } \\
\text { nos pisos superiores. }\end{array}$ \\
\hline
\end{tabular}

No centro das cidades (os de menor dimensão) ou na

Centros Comerciais proximidade de nós de eixos viários periféricos, (os de maior dimensão).

\section{Centro da cidade.}

Centros comerciais.

Franchising
Edifícios com um ou mais pisos construídos ou adaptados para 0 efeito. counts e hipermercados, a sua presença é cada vez menor.

Têm mais de $2500 \mathrm{~m}^{2}$; vasto sortido alimentar e não alimentar de marcas próprias e marcas de referência. Parque de estacionamento.

Coexistem espaços de habitação com espaços de comércio e serviços, de forma dispersa pela território, não consolidando verdadeiros centros/eixos terciários.

São tradicionais ou especializados, com ou sem lojas âncora; podem incluir lazer ou não. Parque de estacionamento.

Lojas que obedeçam aos critérios definidos pela insígnia/master.
Possuem estratégia unívoca na gestão, imagem e modus operandis dos estabelecimentos; diferentes lógicas: selectividade ou saturação territorial.
Parques empresariais, de Nós dos principais eixos escritórios e de ciência e viários. tecnologia
Edifícios com um ou mais pisos construídos para o efeito.
Concentram empresas de tecnologia e ciência; partilham serviços comuns; permitem a instalação de empresas start-ups.

Baseado em Tomé (2011) 
O célere crescimento urbano da Quinta do Conde e as profundas mutações que ocorreram nas últimas quatro décadas na oferta e na procura do comércio e dos serviços justificam a caracterização e a distribuição espacial destas actividades, considerando ainda os impactos (passados, presentes e futuros) da génese ilegal do aglomerado na sua evolução.

\section{QUINTA DO CONDE: EVOLUÇÃO DEMOGRÁFICA E URBANA}

A Quinta do Conde $\left(14,4 \mathrm{~km}^{2}\right)$ é uma das três freguesias do concelho de Sesimbra $\left(194,98 \mathrm{~km}^{2}\right)$ e ocupa uma posição central na Península de Setúbal, fazendo fronteira com os municípios do Seixal, Barreiro e Setúbal. O loteamento ilegal da Quinta do Conde ocorreu em 1971 por iniciativa de António Xavier de Lima, que arrasou a vegetação existente e abriu cerca de $100 \mathrm{~km}$ de arruamentos, segundo uma extensa malha reticular. Com uma área média de $300 \mathrm{~m}^{2}$ por lote, o promotor inicial colocou no mercado 9225 lotes, contemplando alguns espaços para equipamentos colectivos (por exemplo, escolas), ainda que não tivesse qualquer responsabilidade na sua construção.

Para o rápido crescimento da Quinta do Conde contribuíram, além dos aspectos referidos, a sua localização, próximo da Estrada Nacional 10, dos principais pólos empregadores, das praias e de Lisboa (abertura da ponte sobre o Tejo, em 1966), o modus operandis do loteador inicial (o preço era atractivo, por comparação com as áreas congéneres), a facilidade de construir as habitações faseadamente, de acordo com a disponibilidade económica de cada um e a existência de um conflito entre as autarquias de Sesimbra e do Barreiro referente à definição dos limites administrativos, que beneficiou o crescimento exponencial das construções clandestinas, sem fiscalização.

A Quinta do Conde foi a freguesia do país que mais cresceu percentualmente no período intercensitário $1991-2001^{\mathrm{v}}(108 \%)$, e embora o ritmo tenha abrandado entre 2001-2011 (53\%), continuou a registar-se aumento do número de famílias, edifícios e alojamentos (quadro V). A estrutura etária dos residentes na freguesia evidencia um efectivo populacional jovem, com um saldo natural positivo. Note-se ainda que, nestes vintes anos, para os indicadores apresentados, a Quinta do Conde tem ganho importância relativa face ao conjunto do concelho de Sesimbra.

Quadro V - Indicadores demográficos e habitacionais da Quinta do Conde (1991-2011).

Table V-Demographic and housing indicators of Quinta do Conde (1991-2011).

\begin{tabular}{lcccccc}
\hline & \multicolumn{2}{c}{1991} & \multicolumn{2}{c}{2001} & \multicolumn{2}{c}{2011} \\
\hline & $\mathrm{N}^{\mathrm{o}}$ & $\begin{array}{c}\text { Concelho } \\
(\%)\end{array}$ & $\mathrm{N}^{\mathrm{o}}$ & $\begin{array}{c}\text { Concelho } \\
(\%)\end{array}$ & $\mathrm{N}^{\mathrm{o}}$ & $\begin{array}{c}\text { Concelho } \\
(\%)\end{array}$ \\
\hline População residente & 7958 & 30 & 16567 & 45 & 25411 & 52 \\
Famílias & 2516 & 28 & 5656 & 43 & 9906 & 51 \\
Edifícios de habitação & 3977 & 32 & 6257 & 40 & 8414 & 41 \\
Alojamentos & 4669 & 26 & 8856 & 36 & 12429 & 39 \\
\hline
\end{tabular}

Fonte: INE (2009). 
Para estas dinâmicas mais recentes contribuíram, além dos factores referidos, a melhoria da acessibilidade rodoviária a Lisboa (via Ponte 25 de Abril e Ponte Vasco da Gama) e intra-regional (como a A33), bem como a ligação ferroviária entre Lisboa e Setúbal (Fertagus) e a reconversão urbanística encetada em 1982 pela Câmara Municipal de Sesimbra (CMS), com a aplicação do Plano Parcial da Urbanização da Quinta do Conde (PPUQC). Este plano visava reabilitar as áreas de construção ilegal e dotar a Quinta do Conde com a infra-estruturação básica, adaptando-se à malha urbana existente. Todavia, de acordo com Rosado (1997, citado em David, 2002:41-2), "a decisão política era de minimizar os estragos" e acrescenta que o PPUQC "foi a ferramenta possível dentro de uma vontade política para legalizar, organizar e ordenar o que já existia. (...) Talvez pudesse ter sido feito de outra maneira se a filosofia que lhe estivesse subjacente fosse outra."

O PPUQC permitiu, contudo, minimizar os principais problemas do aglomerado, ainda que tenha evidenciado um défice de concretização nos domínios da morfologia urbana e da qualidade do espaço público. Esta última ideia é corroborada por Gaspar, Simões e Barroso (2006), que a sustentam na impossibilidade de identificar os proprietários, uma vez que existiam apenas contratos-promessa de compra e venda, facilmente adulteráveis. Desta forma, a CMS optou por indemnizar grande parte dos proprietários dos lotes destinados a equipamentos colectivos e a espaços verdes.

Estas dinâmicas territoriais e demográficas permitiram, de acordo com os dados apresentados por Tomé (2011), que o valor médio de um lote de terreno com $300 \mathrm{~m}^{2}$ na Quinta do Conde aumentasse de $250 €$ em 1980 para $5000 €$ em 1990 e $90000 €$ em 2000. Mais recentemente, em 2010, o valor diminuiu para cerca de $75000 €$. Não admira, por isso, que a tipologia dos edifícios esteja a mudar da moradia unifamiliar para a moradia bi-familiar e para o bloco de apartamentos com 3 ou mais andares. Com mais de 25000 habitantes, o reforço da densidade populacional, a perspectiva de crescimento e as boas acessibilidades, diversos estabelecimentos de comércio e serviços - de diferentes tipologias - têm-se implantado recentemente na Quinta do Conde.

\section{EVOLUÇÃO DO COMÉRCIO E DOS SERVIÇOS NA QUINTA DO CONDE}

Os primeiros estabelecimentos de comércio e serviços surgiram por volta de 1973, em torno dos principais acessos rodoviários à Quinta do Conde, como a EN10 e a Avenida Principal, por vezes exercendo a actividade na própria residência (na garagem ou mesmo num dos compartimentos da habitação). A oferta comercial era pouco especializada e dominada pelos bens banais (produtos alimentares e utilidades para o lar), materiais de construção civil e serviços pessoais (cabeleireiro). Não raro, estes negócios eram geridos pelas mulheres, que conjugavam as lides domésticas 
com estas actividades, garantindo um complemento ao rendimento do marido, quase sempre operário na indústria ou na construção civil. Com a consolidação do aglomerado e a desindustrialização da Margem Sul (anos 80), a estrutura do negócio mudou, passando as empresas a ter uma índole familiar, trabalhando nela os dois elementos do casal e, por vezes, os filhos. Também se registaram então alterações nos edifícios, passando a ser mais frequentes as moradias isoladas com dois pisos, em que o inferior se destinava ao comércio ou serviços. Por essa altura, instalaram-se as primeiras instituições bancárias na Avenida Principal, a qual assume, desde a génese do aglomerado, "particular importância no contexto urbano, por concentrar grande parte do pequeno e médio comércio, bem como variados serviços, numa zona com tecido urbano já bastante consolidado [e] espera-se que de futuro este espaço veja reforçada a vocação desde sempre assumida, como pólo de atracção do conjunto urbano" (David, 2002: 84).

Em 1985, surgiu o Centro Comercial Europa 3 (CCE), a primeira forma "organizada" de comércio na Quinta do Conde. Apesar da sua localização na principal avenida da vila e próximo do comércio alimentar, o CCE começou a perder a influência na primeira metade da década seguinte devido: à pouca diversidade da oferta; ao aumento da concorrência (interna e externa à Quinta do Conde); à evolução do conceito de centro comercial, que o CCE não acompanhou (deficiente concepção e estrutura física interna; incapacidade de gestão); às mudanças socioeconómicas (maior poder de compra e aumento do parque automóvel da população residente). $\mathrm{Na}$ realidade, embora o CCE seja designado de centro comercial, é um condomínio comercial, sem os atributos necessários para enfrentar a concorrência.

Aquando da abertura do CCE, já existiam o Mercado Municipal e o Mercado de Levante, que operavam juntos no Largo do Mercado. Numa fase inicial, fruto do reforço da oferta comercial, o mercado expandiu-se pelas ruas contíguas, dominando a oferta alimentar no Largo do Mercado (Norte), e a não alimentar ocupava o Largo do Mercado (Sul) e as ruas adjacentes. A dinâmica destes mercados permitiu consolidar uma estrutura comercial na área envolvente (padaria, cafés e pastelarias, lojas de utilidades para o lar) que, com a relocalização dos mercados em 2000, foram perdendo importância e, nalguns casos, encerraram ou mudaram de actividade.

A inauguração do novo Mercado Municipal dotou a Quinta do Conde de uma infra-estrutura equipada com 48 bancas, com melhores condições de higiene e conservação alimentar e uma galeria comercial com 25 lojas (interiores e exteriores). Se aquando da abertura do mercado as lojas interiores apresentavam uma oferta pouco qualificada e com concorrência relativamente próxima, o que inviabilizou a consolidação deste espaço comercial, hoje apresentam maior dinamismo e especialização (agência de viagens e sapateiro, entre outros). Os estabelecimentos exteriores funcionam como complemento da oferta do mercado (caso dos talhos e utilidades para o lar), mas exercem também outras funções que ajudaram a consolidar este espaço comercial (como papelaria, cabeleireiro, centro de estética e serviços municipais). Já o mercado de levante tem perdido relevância, visível pela redução do seu perímetro e, mais recentemente, pela sua suspensão até à aprovação do Plano de Ordenamento 
da Venda Ambulante. A relocalização dos mercados permitiu a requalificação do tecido urbano e a emergência de uma área comercial com mais qualidade - a Baixa da Quinta do Conde. Dada a importância estratégica desta área, a CMS fez uma intervenção urbanística, em 2000, visando organizar a circulação automóvel, ampliar o estacionamento, qualificar a circulação pedonal e criar um espaço público aberto, com uma estrutura polivalente de apoio ao comércio e serviços e acolhimento de actividades socioculturais.

A partir de meados dos anos 90, em virtude do reforço da população, da mudança do perfil demográfico e da melhoria das acessibilidades, começaram a surgir lojas das cadeias de distribuição. A primeira insígnia foi o Minipreço (1994), implantando-se no espaço urbano consolidado da Avenida Principal, próximo do cliente e com fácil acesso. Anos mais tarde, surgiram os primeiros supermercados - Modelo (em 2000 complementado com a Modalfa e a Worten), Plus (2001), Lidl (2007), Feira Nova (2007; com a Get e a New Code) e Aldi (2011), privilegiando uma lógica de proximidade entre si e de fácil acesso à EN 10. O impacto da abertura das primeiras superfícies comerciais foi grande, com reflexos na perda de vendas do comércio tradicional e no encerramento de alguns estabelecimentos. Outros mantêm-se em funcionamento, com menos pessoal e diversificando a oferta. As actividades relacionadas com a alimentação, tecnologia e pronto-a-vestir foram as mais afectadas (Tomé, 2011). Já as unidades que abriram depois de 2007 não tiveram impactos relevantes no pequeno e médio comércio, concorrendo sobretudo com as estruturas similares. Do ponto de vista urbanístico, a implantação destas superfícies - sobretudo das primeiras - permitiu requalificar a Urbanização Cova dos Vidros, originando uma nova centralidade urbana ${ }^{\text {vi }}$ beneficiada, mais tarde, com a construção do Parque da Vila, cujos custos financeiros foram suportados por uma das insígnias.

Nos últimos quinze anos têm-se destacado ainda outros eixos comerciais, em função dos percursos/paragens dos autocarros da SulFertagus, que fazem a ligação à estação de Coina: a Avenida da Liberdade, onde já havia algum comércio desde o loteamento inicial; e as Ruas Manuel de Arriaga (próxima do actual Mercado Municipal) e Serra da Arrábida, onde se desenvolveu a construção em altura (3/4 pisos), destinando-se o piso térreo ao comércio e serviços. Na primeira rua destaca-se a oferta de utilidades para o lar, artigos de papelaria e escolares e cuidados pessoais e na segunda, cafés, pastelaria, padaria, minimercado, talhos e charcutaria (Tomé, 2011). Ou seja, na área de maior densidade populacional e oferta comercial começa a esboçar-se uma tendência de especialização por eixos.

O levantamento funcional realizado na área de estudo, em Janeiro de 2011, permitiu contabilizar 989 espaços destinados ao comércio e serviços, distribuídos por 147 ruas ( 12 das quais reúnem $51 \%$ dos estabelecimentos e 37 ruas concentram $75 \%)$. A Quinta do Conde 1 é a área que concentra mais estabelecimentos $(29,9 \%)$, ao invés da Quinta do Conde 4 (7,2\%) (fig. 2). Do total de espaços de comércio e serviços, 198 (20,0\%) estavam sem ocupação, dos quais 140 (14,2\%) se encontravam para venda ou aluguer (Tomé, 2011). 


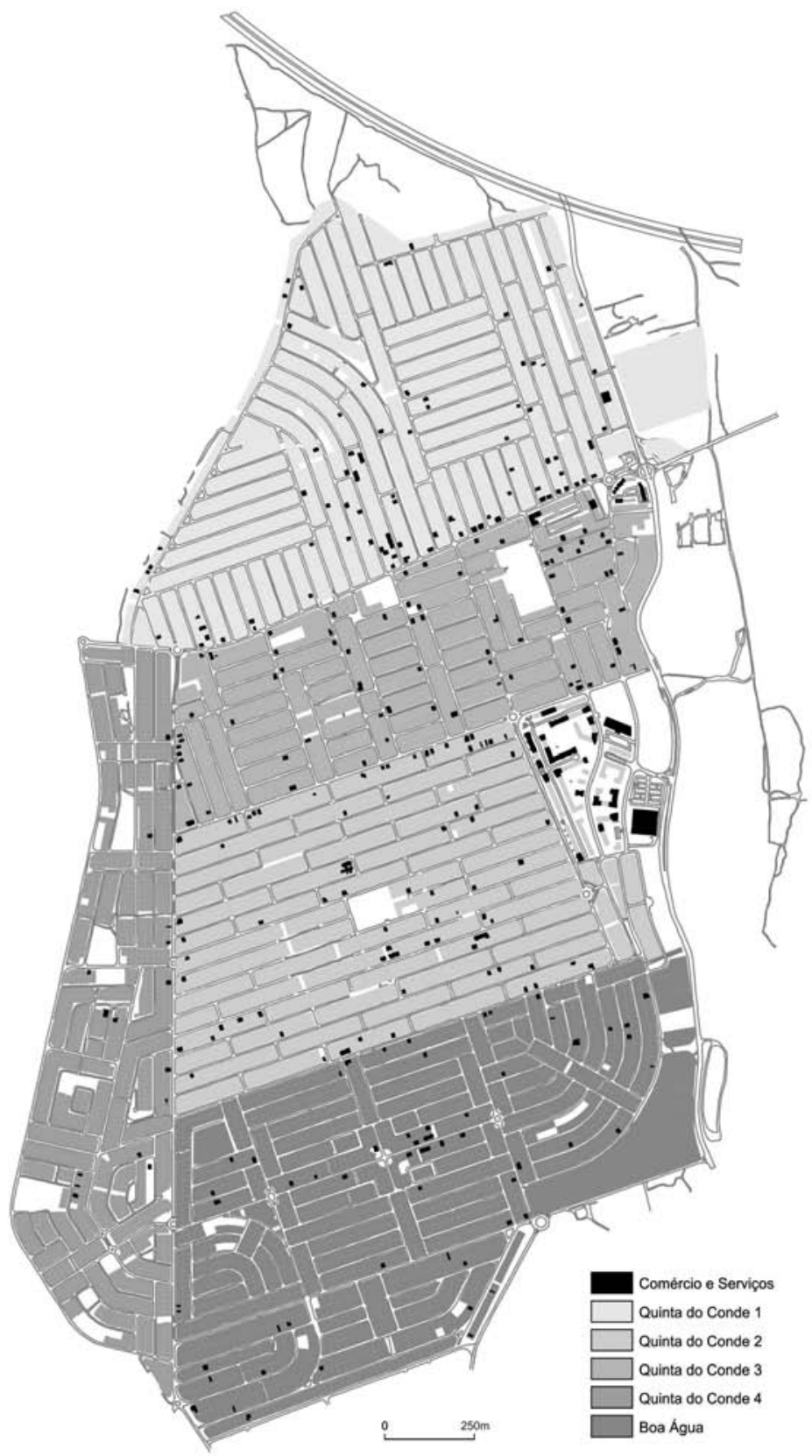

Fig. 2 - Comércio e serviços da Quinta do Conde (2011).

Fig. 2 - Trade and services in Quinta do Conde (2011).

Nota de leitura: As várias tramas, além de evidenciarem as principais áreas geográficas da freguesia, permitem mostrar os diferentes ritmos de expansão: o aglomerado desenvolveu-se na área a cinzento, enquanto a área com as áreas com trama mais escura correspondem à expansão mais recente. 
Atendendo à função principal dos estabelecimentos de comércio e serviços, agrupada de acordo com uma classificação adaptada de Barata Salgueiro (1996), constata-se que as actividades dominantes na Quinta do Conde são o alojamento e a restauração, os serviços à colectividade e os serviços pessoais (quadro VI).

Quadro VI - Função principal dos estabelecimentos de comércio e serviços da Quinta do Conde (Q.C.).

Table VI-Main function of establishments of retail trade and services of Quinta do Conde.

\begin{tabular}{lccccccc}
\hline \multirow{2}{*}{ Função Principal } & Q.C. 1 & Q.C. 2 & Q.C. 3 & Q.C. 4 & Boa Água & \multicolumn{2}{c}{ Total Geral } \\
\cline { 2 - 8 } & N. $^{\text {o }}$ & N. $^{\text {o }}$ & N. $^{\text {o }}$ & N. $^{\text {o }}$ & N. $^{\text {o }}$ & N. $^{\text {o }}$ & $\%$ \\
\hline Alojamento/restauração & 45 & 42 & 42 & 13 & 18 & $\mathbf{1 6 0}$ & $\mathbf{2 0 , 4}$ \\
Serviços à colectividade & 29 & 22 & 34 & 4 & 10 & $\mathbf{9 9}$ & $\mathbf{1 2 , 6}$ \\
Serviços pessoais & 30 & 23 & 36 & 1 & 6 & $\mathbf{9 6}$ & $\mathbf{1 2 , 2}$ \\
Serviços financeiros & 37 & 13 & 29 & & 6 & $\mathbf{8 5}$ & $\mathbf{1 0 , 8}$ \\
Serviços de reparação & 15 & 12 & 16 & 4 & 12 & $\mathbf{5 9}$ & $\mathbf{7 , 5}$ \\
Produtos alimentares & 12 & 8 & 13 & 3 & 9 & $\mathbf{4 5}$ & 5,7 \\
Artigos pessoais & 10 & 8 & 19 & 6 & 2 & $\mathbf{4 5}$ & $\mathbf{5 , 7}$ \\
Serviços técnicos & 12 & 9 & 10 & 4 & 8 & $\mathbf{4 3}$ & $\mathbf{5 , 5}$ \\
Artigos lazer-cultura & 7 & 9 & 9 & 4 & 2 & $\mathbf{3 1}$ & $\mathbf{3 , 9}$ \\
Equipamento para o lar & 3 & 5 & 7 & 7 & & 22 & 2,8 \\
Combustíveis/transportes & 11 & 2 & 6 & 3 & & 22 & 2,8 \\
Equipamento profissional & 6 & 4 & 6 & & 4 & $\mathbf{2 0}$ & $\mathbf{2 , 5}$ \\
Higiene, saúde e beleza & 7 & 2 & 8 & 1 & 1 & $\mathbf{1 9}$ & $\mathbf{2 , 4}$ \\
Construção/bricolage & 6 & 1 & 4 & 6 & 2 & $\mathbf{1 9}$ & $\mathbf{2 , 4}$ \\
Comércio não especializado & 4 & 4 & 4 & 1 & 2 & $\mathbf{1 5}$ & $\mathbf{1 , 9}$ \\
Serviços recreativos-culturais & 1 & 1 & 3 & & 1 & $\mathbf{6}$ & $\mathbf{0 , 8}$ \\
\hline
\end{tabular}

Fonte: Tomé (2011)

A partir da observação do quadro podemos concluir que há uma predominância dos serviços face ao comércio, o que reflecte não só a importância assumida pela restauração (cafés, pastelarias, etc.), mas também mudanças no comportamento dos consumidores, que adquirem cada vez mais bens e serviços que implicam uma personalização/acréscimo de valor; aplicando a ideia expressa anteriormente ao sector da alimentação, houve uma crescente procura por refeições prontas (em restaurantes ou para levar para casa), resultado da entrada da mulher no mundo do trabalho, da diversidade de tipo de famílias e do carácter de dormitório que a Quinta do Conde tem assumido na última fase de expansão; e as unidades de produtos alimentares (supermercados de cadeias de distribuição) ocupam, em termos relativos, um lugar modesto, mas serão, porventura, as que mais facturam e as que têm maior área de influência.

Em suma, pode afirmar-se que nas últimas duas décadas houve uma profunda mutação na estrutura do comércio e serviços da Quinta do Conde, traduzida no reforço da oferta, no predomínio dos serviços sobre o comércio e na presença de 
insígnias da distribuição alimentar e não alimentar. Em paralelo, assistiu-se à diminuição do número de estabelecimentos de produtos alimentares, artigos pessoais e equipamento para o lar, incapazes de se modernizarem para fazer frente à concorrência. Os comerciantes, já idosos e pouco receptivos às mudanças, aproveitaram o novo contexto comercial para se aposentarem. Acresce que a influência dos centros comerciais mais próximos e de algumas insígnias especializadas que se têm instalado na sua envolvência, fazem com que diversos ramos de actividade não consigam vingar na Quinta do Conde, como é o caso dopronto-a-vestir, sapatarias, lojas de informática e telecomunicações, tendo já encerrado alguns dos mais antigos (Tomé, 2011).

Com a mudança de paradigma na construção civil na Quinta do Conde (passagem da auto-construção de moradias unifamiliares para a construção de edifícios bifamiliares e plurifamiliares por empresas especializadas) houve também uma redução do número de empresas de materiais de construção; ao invés, assistiu-se à abertura de várias agências imobiliárias (uma das actividades com maior sucesso na década de 90), uma vez que o mercado de venda e aluguer de imóveis se mantém dinâmico.

Os estabelecimentos de comércio e serviços da Quinta do Conde apresentam algumas singularidades de inserção urbana, em função da evolução do aglomerado. A maioria das funções são exercidas em edifícios destinados a habitações uni, bi ou plurifamiliares. O número de edifícios com uso exclusivo de comércio e serviços ronda os $16,5 \%$. No que concerne à repartição por pisos, $90,1 \%$ dos espaços ocupam o piso térreo e $6,3 \%$ o primeiro andar. Cerca de $0,7 \%$ das actividades estão implantadas em caves e as restantes $(2,5 \%)$, sobretudo serviços, entre os pisos 2 e 5 (Tomé, 2011).

Importa ainda referir que a Quinta do Conde tem fraca capacidade de atracção para além do próprio aglomerado, exceptuando duas funções: os laboratórios de análises clínicas e o Cartório Notarial. Os supermercados da Quinta do Conde também têm aumentado a área de influência, levando alguns moradores de Azeitão e Fernão Ferro a fazer aí compras. Ainda assim, muitos desses consumidores fazem-no por opção, uma vez que têm outras alternativas nas suas áreas de residência (Tomé, 2011).

\section{CONCLUSÃO}

Os espaços suburbanos são hoje áreas multifuncionais e multipolares, onde existe uma diversidade de actividades de comércio e de serviços, fragmentando o espaço urbano e dificultando a sua delimitação geográfica. Estes espaços - sem cultura, história e identidade - foram construídos em torno da cidade central (a cidade velha, com história e grande pólo dinamizador da região) e dos múltiplos pólos dispersos pelo vasto território e com funções distintas (residência, emprego, equipa- 
mentos colectivos e espaços de recreio e lazer), permitidas pelo transporte individual motorizado. Para esta situação também contribuíram as AUGI, que, apesar de todos os aspectos negativos associados, foram uma resposta para o problema da habitação que existia em Portugal evitando maior proliferação de formas de habitação precárias como os bairros de barracas, facilitando a adaptação de um novo modo de vida com formas complementares de rendimento.

Atendendo à época e ao contexto histórico em que surgiu, o loteamento ilegal da Quinta do Conde apresentava diversas características que facilitaram a sua reconversão como a estruturação e hierarquização do sistema urbano e viário, com um traçado ortogonal; a evolução da ocupação do território, gerida nas primeiras décadas por António Xavier de Lima e a afectação de áreas para a construção de equipamentos colectivos. Contudo, importa não esquecer, por exemplo, que a hierarquização do sistema urbano se revelou deficiente, os arruamentos demasiados estreitos e os lotes com áreas insuficientes, sobretudo, os que se destinavam aos espaços e equipamentos públicos, o que condicionou, e ainda condiciona, o desenvolvimento do comércio e dos serviços. Neste sentido, urge ultrapassar ou, pelo menos, tentar minorar alguns destes problemas, designadamente: (i) a rede viária, reorganizada no início desta década com o objectivo de fluir melhor o trânsito, mas que ainda é problemática nalguns pontos da vila; (ii) a insuficiência de bolsas de estacionamento; (iii) a integração deficitária entre espaços pedonais e espaços de comércio e de serviços; (iv) a não articulação entre espaços de recreio e lazer e os espaços afectos a usos terciários; (v) a criação excessiva de espaços destinados ao comércio e serviços na década de 90, para os quais não há procura e, por isso, estão (e estarão) sem ocupação; e (vi) a ausência de capital para investir e de visão estratégica dos empresários locais.

Os resultados desta investigação podem não ser generalizáveis a outras AUGI, uma vez que as realidades são muito diversas. Por conseguinte, cada AUGI deve ser analisada sem preconceitos ou estigmas sociais, visto que a falta de qualidade do espaço urbano não depende apenas da origem clandestina do aglomerado; muitos loteamentos legais apresentam igualmente um défice de qualidade. Contudo, esta investigação teve como mais-valia: estudar as AUGI por prismas menos convencionais, o que deve ser incentivado; sintetizar as dinâmicas do comércio e serviços em espaços suburbanos específicos, em detrimento da tradicional visão dicotómica centro/periferia; e contribuir para a difusão de produção científica sobre estas temáticas e, em particular sobre a Quinta do Conde, uma vez que ela ainda é diminuta.

\section{AGRADECIMENTOS}

O autor agradece as sugestões e comentários aos revisores científicos e editores da Finisterra, tal como ao Professor Doutor José Afonso Teixeira, que contribuíram substancialmente para a melhoria da qualidade do artigo. 


\section{BIBLIOGRAFIA}

Alves T (2005) Geografia dos serviços: reestruturação produtiva e inovação social. Centro de Estudos Geográficos, Lisboa.

Arrabaça P (2002) Formas urbanas na cidade construída: Agualva-Cacém, 1953-2001. Dissertação de Mestrado, Universidade de Lisboa, Lisboa.

Barata Salgueiro T (2005) A cidade como espaço de vida e lugar de produção. In Medeiros C A (dir.) Geografia de Portugal - Sociedade, paisagens e cidades, Círculo de Leitores, Lisboa: 305-406.

Barata Salgueiro T (1996) Do comércio à distribuição. Roteiro de uma mudança. Celta Editora, Oeiras.

Barata Salgueiro T (1989) Novas formas de comércio. Finisterra-Revista Portuguesa de Geografia, XXIV(48): 151-217.

Barata Salgueiro T (1983) Mercado de habitação e estrutura urbana na área suburbana de Lisboa. Separata do Boletim Cultural da Assembleia Distrital de Lisboa, n. ${ }^{\circ} 89$.

Barata Salgueiro T (1977) Bairros clandestinos na periferia de Lisboa. Finisterra-Revista Portuguesa de Geografia, XII(23): 28-55.

Barata Salgueiro T (1972) Bairros clandestinos na periferia de Lisboa. Centro de Estudos Geográficos, Lisboa.

Bruno Soares L (1989) Planeamento em áreas de crescimento urbano ilegal. In DGOT (eds.) Encontros sobre construção clandestina - volume II, Edição DGOT, Lisboa: 33-40.

Bruno Soares L (1984) Urbanização clandestina e política urbana. Sociedade e Território, 1: 19-34.

Bruno Soares L (1982) Habitação clandestina. Cadernos Municipais, 15: 32-36.

Cachinho H (1992) O comércio a retalho na Área Metropolitana de Lisboa: patologias e potencialidades de um sector em mutação. Sociedade e Território, 17: 26-37.

Cachinho H (2006) O comércio retalhista: da oferta de bens às experiências de vida. In Medeiros
C A (dir.) Geografia de Portugal - Actividades económicas e espaço geográfico, Círculo de Leitores, Lisboa: 266-331.

Costa D (2008) As áreas urbanas de génese ilegal contributos para um modelo de avaliação de desempenho urbanístico. Dissertação de Mestrado, Universidade Técnica de Lisboa, Lisboa.

David N (2002) Os espaços abertos públicos da Quinta do Conde. Dissertação de Licenciatura, Universidade de Évora, Évora.

DGOTDU (2005) Vocabulário de termos e conceitos do ordenamento do território. DGOTDU, Lisboa.

Gaspar J, Simões J M, Barroso S (2006) Expansão, reabilitação e renovação urbana: lições da experiência. In Medeiros C A (dir.) Geografia de Portugal - Planeamento e Ordenamento do Território, Círculo de Leitores, Lisboa: 345-441.

Guerra I, Fonseca Ferreira A (1990) Le mouvement 'clandestin' au Portugal - petites ressources, grands investissements. Sociedade e Território, n. $^{\circ}$ especial: $115-120$.

INE (2009) O país em números - Edição 2008. Lisboa.

Matos F L (1990) A construção clandestina em Vila Nova de Gaia - o caso dos bairros do Picão e da Madalena Nascente. Revista da Faculdade de Letras - Geografia, VI: 149-280.

Merenne-Schoumaker B (2003) Géographie des services et des commerces. Presses Universitaires de Rennes, Rennes.

Monnet J (2000) Les dimensions symboliques de la centralité. Cahiers de Géographie du Québec, 44(123): 399-418.

Nunes da Silva F, Pereira M (1986) Ilusões e desilusões das periferias na Área Metropolitana de Lisboa. Sociedade e Território, 5: 14-24.

Tomé R (2011) Comércio e serviços em Áreas Urbanas de Génese Ilegal: o caso da Quinta do Conde. Dissertação de Mestrado, Universidade Nova de Lisboa, Lisboa.

i O conceito de Área Urbana de Génese Ilegal (AUGI) apenas é introduzido com a Lei n. ${ }^{\circ}$ 91/95, de 2 de Setembro, alterada pelas Leis n. ${ }^{\circ}$ 165/99 (de 14 de Setembro), 64/2003 (de 23 de Agosto) e 10/2008 (de 20 de Fevereiro). 
ii Elementos inquiridos: nome do estabelecimento; função principal e secundária; estado de conservação do edifício e da fachada comercial; qualidade da iluminação, montra e disposição dos produtos; elementos acessórios existentes (sinalética, sistemas de aquecimento, ventilação e ar condicionado e toldos); mudanças de proprietário e função.

iii Entende-se por consumismo, a aquisição de produtos ou serviços supérfluos, de forma ego centrada, indiscriminada e impulsiva, por vezes, sem os recursos financeiros necessários, enquanto consumerismo é apreendido como um comportamento de consumo responsável, com consciências dos impactos individuais e colectivos desse ato, promovendo uma relação equilibrada entre os produtores, os distribuidores e os consumidores.

iv O conceito de centro de comércio tradicional adoptado nesta investigação considera a área da cidade (não necessariamente o seu "centro geográfico"), onde se concentram o comércio e os serviços, dinamizando-a através da criação de emprego e da atracção de consumidores e visitantes (Barata Salgueiro, 1996).

v Em virtude da freguesia da Quinta do Conde só ter sido criada em 1985, não foi possível fazer uma comparação com as dinâmicas demográficas e habitacionais apresentadas nos Censos de 1981.

vi Por centralidade urbana entende-se as dinâmicas positivas e negativas geradas pela distribuição e respectivas interacções sociais e territoriais das várias funções do espaço urbano (habitação, comércio, serviços, recreio e lazer), na qual a acessibilidade pedonal e rodoviária desempenha um papel essencial (Monnet, 2000). 